\title{
THE CONSOLIDATION OF FOREST TERRITORIES AS A TOOL TO IMPROVE THEIR MANAGEMENT
}

\author{
Nikolay Neykov ${ }^{1}$, Petar Antov ${ }^{2}$, Ilko Dobrichov ${ }^{3}$, Aureliu-Florin Halalisan ${ }^{4}$, \\ Emil Kitchoukov ${ }^{5}$
}

\begin{abstract}
Land consolidation in forest areas is a problem that has been prevalent in Bulgaria in recent years. This is a problem in all forests where ownership is distributed between the State, municipalities and private owners. Timber harvesting and exportation is much easier and cheaper when access is easier. This article summarizes the main directions of forest land consolidation, highlighting the leading understanding in scientific research to date. The purpose of the study is to provide some basic steps related to forest territory consolidation that allow to determine its economic effectiveness. The current paper is the first step in developing an optimization model to support the forestry units in Bulgaria and in other countries which have undertaken such a difficult task.
\end{abstract}

JEL Classification Numbers: B41, Q23, P51, DOI: https://doi.org/10.12955/peb.v1.28

Keywords: forest land, consolidation, forest management

\section{Introduction}

The problems with ownership of forest areas are the typical issues of the forest management over many years. The land structure is one of the main components of the forest activities planning. The main goal of forest land consolidation is often to improve the usability of the area for commercial forestry, but depending on the country and the location, environmental issues may also be important (Kolis et al., 2017). The State agencies charged with territory stewardship would operate more efficiently if they could share a standardized cadaster base (Endo, 2010). The increasing fragmentation of privately-owned forest land represents a main challenge for the future supply of wood raw material in the forest-based sector (Kies \& Peter, 2017). In this context, land consolidation means a comprehensive reallocation procedure of a rural area consisting of fragmented agricultural or forest holdings or their parts (Vitikainen, 2004).

The forestry sector of the Republic of Bulgaria provides the raw material base for the wood-processing and furniture industries. Wood and other products extracted from the Bulgarian forest are an important energy source that is self-renewable, but at the same time is a limited resource. Therefore, a radical reform needs to be experienced by the Bulgarian forestry authorities for at least ten years with the ultimate goal of establishing a market economy in the forestry sector, a part of which is the forest land consolidation. The market economy principles should ensure the most efficient use of forest resources and enable the achievement of economic objectives at the lowest cost.

State forestry departments in Bulgaria, as well as in other countries, are entities, for which the principle of budgetary funding has been removed. They manage the forests and lands of the state forestry fund within their defined territorial scope of activity. In a competitive environment, these enterprises are mostly self-financed from their revenues and from the realized profits they can accumulate funds for investments in forests. This is also the reason why the consolidation of land properties in the forest territories is the subject of a detailed study.

To date, there is no comprehensive, unified and clearly formulated methodology for assessing the effects of forest land consolidation in the Bulgarian forest sector. The consolidation procedures carried out so far by the Bulgarian forest authorities aimed at achieving greater efficiency for timber harvesting and other objectives with non-economic effects. The so-called first stage in 2016 was a kind of experiment with consolidation of forest areas. Its combined effect is still not clear neither for the authorities nor for the academics. The opinion of many forestry professionals is that it was successful. For this reason the Ministry of Agriculture, Food and Forestry decided to repeat the "experiment". At present, the so-called second stage of consolidation, for which 1,000,000 Euro has been allocated, is being implemented. The previous stage, carried out in 2016, cost 350,000 Euro. All the explained features of forest land

\footnotetext{
${ }^{1}$ University of Forestry, Sofia, Bulgaria, Faculty of Business Management, nneykov@ltu.bg

${ }^{2}$ University of Forestry, Sofia, Bulgaria, Faculty of Forest Industry, p.antov@ltu.bg

${ }^{3}$ University of Forestry, Sofia, Bulgaria, Faculty of Forestry, nneykov@ltu.bg

${ }^{4}$ Transilvania University of Brasov, Romania, aureliu.halalisan@ unitbv.ro

${ }^{5}$ University of Forestry, Sofia, Bulgaria, Faculty of Business Management, ekitchoukov@ltu.bg
} 
consolidation in Bulgaria determine the need of placing the hypothesis about the effects of its commitment. The purpose of this study is to provide some basic steps in forest land consolidation that allow to determine its economic effectiveness and make suggestions about the broader effects on the forestry sector. The study is conducted under the conditions of limited information about consolidation and exploits only data available in the statistical databases.

\section{The benefits of forest land consolidation as a managerial goal}

Vitikaninen (2004) distinguished the following land consolidation objectives: Objective of improvement: division of agricultural, forest land and land properties in villages; infrastructure, i.e. roads, piping, drainages. Every transfer of land from one type of property to another allows implementing decisions in different areas of forest management. Consolidation as an approach for this, gives an opportunity to implement decisions of the forest authorities in efficient scale. Building drainages and roads require the appropriate revenues so as to generate returns in the short or long term.

Projects development and implementation. All the activities undertaken by the forest authorities (whatever they are) for achieving the aims placed in strategies can be considered like projects. Consolidation of forest lands gives the freedom and greater opportunities to commit the project activities.

Thomas (2004) grouped the land consolidation objectives into several categories related to: agriculture/forestry; transport; regional water management; communal development; environmental protection/supply-waste disposal; nature protection/landscape and leisure/recreation. It is obvious that the land consolidation can be a powerful tool for achieving various managerial goals. In forestry the goals can be narrowed. The goals are driven dominantly by the forest owners or forest authorities which administer the planting and harvesting. According to Kies \& Peter (2017) consolidation leads to eased access to areas, and an increase of harvesting volumes and activation of non-managed areas. Infrastructure improvement after consolidation would increase the timber been harvested, and consequently turnovers. From the research that has been done, it is relatively clear that the land consolidation in forest areas influences both revenue (turnover) side and costs side of the forest management. According to Hudecová (2015) the most prominent benefits include the alignment of the actual state, the legal state and registered state, and the creation of new cadastral map of the highest positional accuracy. This is a kind of indirect benefit, derived from economies of the ease in managing the territories.

\section{Costs for land consolidation}

According to Vitikaninen (2004) the costs of the land consolidation procedure can be divided into two groups:

Costs for the consolidation preparation. They include all the permanent costs during the procedure of the preparation like wages and salaries, material costs, energy and indirect costs for the departments involved in preparation like depreciation costs etc. These costs may be implicit ones if the procedure is maintained by the exclusively created departments or teams.

Implementation costs include the cost for the construction works and design of the roads and drainage network. The costs also include planning and construction costs for other associated projects implemented in connection with the land consolidation project, demarcation costs, and auxiliary personnel, etc.

The costs are directly connected to the steps of the consolidation process. In line with the Vitikainen (2004), Kies \& Peter (2017) established the two types of costs in their analysis, i.e. for procedures and implementation. Here appears the question of the essence of the procedures. In countries like Germany the forest land consolidation takes several years for the areas to be fully consolidated and to provide the productivity under forest managing institution.

\section{Campaign for forest areas consolidation (FAC) in Bulgaria}

In Bulgaria, the case is not entirely the same as in other European countries (Germany, Finland, Sweden) which outlines some differences in FAC. The costs that appeared in the Bulgarian forest land consolidation campaign are not estimated to date. Their existence can only be indicated in a general way. The main element of FAC which is one of the costs inducing sources is the FAC administration 
unit. According to the order (Order No49-336-2019) of Minister of Agriculture, Food and Forestry, the authorities that commit the FAC are:

- Ministry of Agriculture, Food and Forestry (MAFF)

- Executive Forest Agency (EFA) and its departments (Regional Directorates - RD)

- Forest Enterprises (FE) and their departments (FED)

The previous stage of forest consolidation campaign was implemented by the same authorities which all generate costs. These costs can be classified as direct and fixed in respect of land areas. The main purpose of consolidation is to enlarge the state-owned land at the expense of the privately-owned. This way MAFF aims to strengthen the control over forests and force their protective functions. The campaigns in 2019 and in 2016 required each individual land purchased to be within the interval of 0.15 ha. This requirement provides agility of decisions and appropriate allocation of the areas. At the same time, it places doubts if it is necessary to produce costs for activities with a small effect. For the purposes of the current study the procedure is divided into the following steps:

Step 1: Director of the FED shall create a committee which has to review the proposals from private owners for selling their land to state. The committee shall prescreen the proposals that fill the requirements (land/areas to be up to 5 ha, to be close to forest roads and other state areas).

Step 2: Prescreened areas will be classified and the selling price offers given by the private owners shall be opened. At the same time, the committee shall negotiate with experts' assessments of the areas so as to propose buyer prices.

Step 3: The committee shall classify the proposals based on the minimal difference between buyer and seller's price. The land properties (areas) that fall into the amount of the subsidy for the FED shall be proposed to bargain.

All the steps of FAC finish at the third step. After that the activities for roads, drainages, demarcation etc. are committed. Until now there is no official statistical data about the activities described. It is a subject of future research. In many cases the requirements to the land properties provoke some of subsequent activities to be omitted. It becomes clear that if the steps above accomplish the overall process of FAC, and the areas are not for harvesting, but for protection, recreation etc., the costs for implementation are zero. In this context the optimization of the FAC should be adapted to the specific benefits.

\section{Materials and methods}

Statistical methods and basic economic indicators for identification of the effects of the previous campaign on the economic conditions of the Bulgarian forestry were used in this study. The stepwise

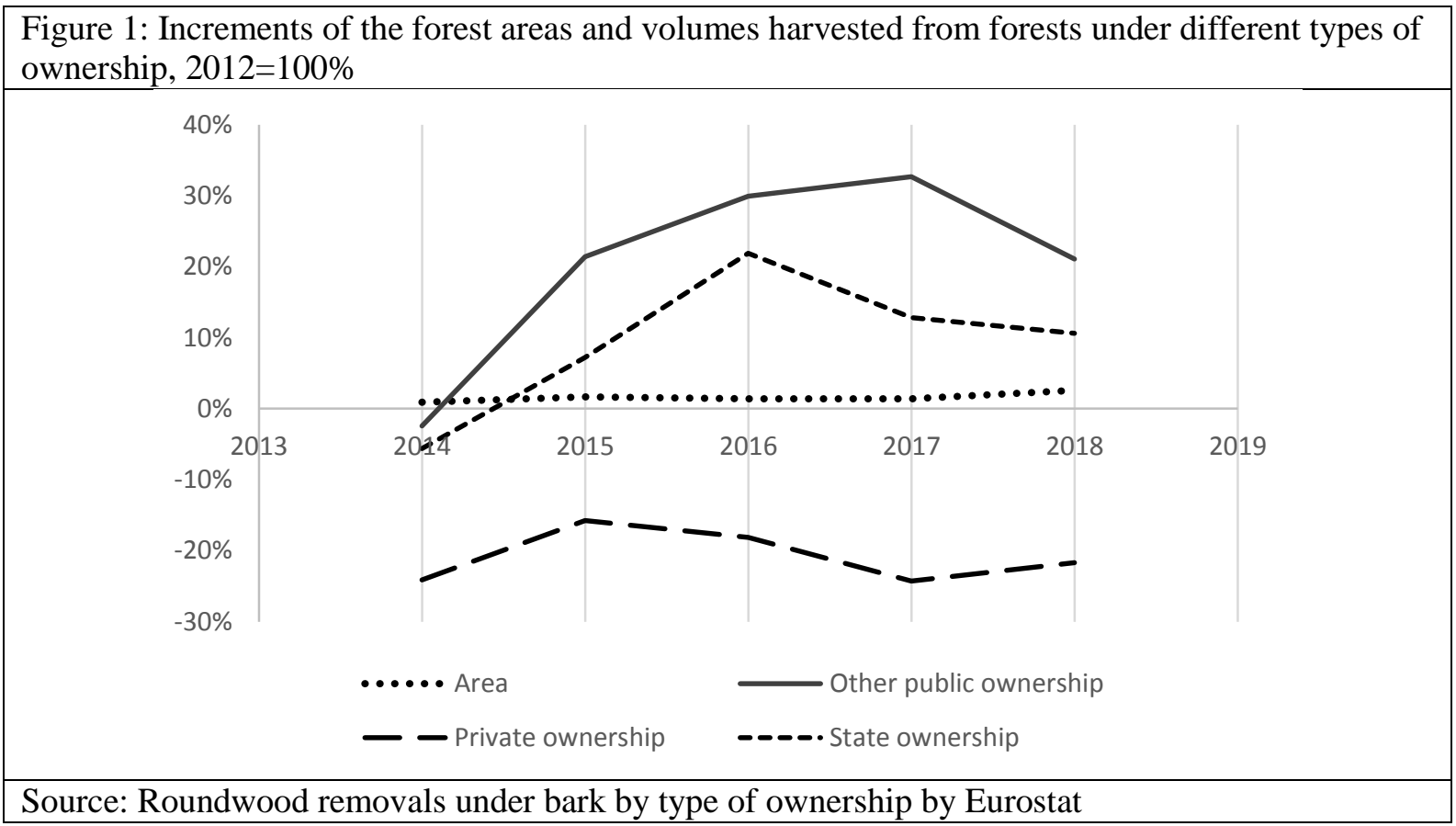


approach proposed here for preliminary determination of the effectiveness of the procedure for areas selection to be included in the current campaign is based on the previous one, carried out in 2016.

Statistical approaches used are non-parametric tests for statistical significance of the differences between economic indicators before and after forest land consolidation. Wilcoxon signed rank test was used as the most appropriate for the purpose. The test aims to detect differences between variables from the same sample before and after an intervention by calculating the differences between their ranks. Tests were conducted in comparison of the RDs in the selling state owned land to private or other public customers before and after the 2016 campaign.

Trend line analyses in the forest areas before, during and after years of 2016 campaign.

Data used in this study was taken from the Eurostat statistics for forestry, EFA reports and statistics. The time periods considered were: 2014-2019 for the RDs comparison and 2010-2017 for the Economic Ratios. Trend line analysis was made for the period 2009 and 2015/2018.

\section{Results and discussion}

The first comparison in the analysis encompasses the dynamic characteristics of the harvesting and land square, shown in Fig.1.

The graph shows that since the forest consolidation campaign has been undertaken in 2016, the use of timber from private forests has increased after campaign accomplishment in 2017. The trend started after 2015 is interrupted. It can be assumed that the campaign was intended to intensify timber harvesting from private forests, leaving the non-economic benefits of forests in the hands of the State. Therefore, the first step in the consolidation process has to be the decision in whose ownership the economic benefits should remain after the consolidation. It is a kind of solution for the distribution of economic goods and value added between private forest owners and the public one in the face of state-owned enterprises. According to the objectives, described by Thomas (2004), the consolidation in 2016 achieved non-economic objectives for the State forests. The results from the 2016 consolidation in the Bulgarian Forestry gave indirect economic benefits to the society throughout forests reservation. This places in doubt the fairness of the process in terms of short run benefits for public forests owners, i.e. society-as-a-whole. The distribution of benefits throughout forestry have been extensively studied (Reference Yovkov \& Kolev 2008; Kolev \& Yovkov, 2011), which state that the fairness is achievable if the distribution is almost $50 \% / 50 \%$ between society and the forest owners. Therefore, the consolidation until now did not clearly achieve fair distribution of goods from forests, like revenues from harvested timber and possibilities to have them in the future for the public-owned forest resources. Figure 2 presents some hidden results that appeared after the consolidation in 2016.

Figure 2 reveals that the only incomes appeared to increase after the consolidation are the labour incomes. Their increment outruns the increment of the production. After the consolidation the subsidies

\begin{tabular}{|c|c|c|}
\hline Figure 2: Increments of the economic indicators before and after consolidation in 2016, 2012=100\% \\
\hline $60 \%$ \\
$40 \%$ \\
$20 \%$ \\
$0 \%$
\end{tabular}


and the labor costs determined high costs from national budget and budgets of the FEs. The productivity increment does not exceed the increment of the labor costs. This means that the resources became more expensive due to bureaucratic decisions.

In fact, the forest land consolidation was not the only reason for all changes occurred in the Bulgarian Forestry. The years when the first consolidation occurred revealed the entire strategic orientation of the Forestry, from which the consolidation was just a small part. The purposes placed in the strategy for Bulgarian Forest Sector in 2013 (National Strategy for Improvement of Bulgarian Forest Sector 20122020) are improving the productivity, preservation of biodiversity and use the forests for green economy paradigm. The changes after the previous consolidation can be supposed to be more focused on giving the productivity in hands of private forest owners, in expense to state committed forest utilization. The reduction of the net entrepreneurial income suggests that the remained forest managed by the private owners are planted with less valuable timber. This can be assumed as one of the hidden purposes of the consolidation in previous and current campaigns to push the private sector into a low-price segment.

One process was ultimately changed after the consolidation, namely the process of selling state forests to different than state owners. It became statistically significant after the commitment of the previous consolidation from 2016 to 2018. The Wilcoxon rank-sum test was conducted (see Table 1).

\begin{tabular}{|c|c|c|}
\hline \multicolumn{3}{|c|}{ Wilcoxon signed-rank test } \\
\hline $\mathrm{H}_{0}$ & $\mathrm{p}$ & $\alpha$ \\
\hline signrank y2015 = y2016 & Prob $>|z|=0.0090$ & \multirow{3}{*}{0.05} \\
\hline signrank y2015 = y2017 & Prob $>|z|=0.1386$ & \\
\hline signrank y2015 = y2018 & Prob $>|z|=0.0209$ & \\
\hline
\end{tabular}

The data given in Table 1 show that in 2016 and 2018 the sales of state-owned land is different than in 2015. The latter was the last year when the state forests were sold to private or other public owners. Complementing with the lines in Figure 1, the main recipients of new forest lands were some of the official religious institutions or ministries, which take the profits for themselves, i.e. the forests did not have the function of state-ownership in the meaning of the property providing contribution to the forests management in the country.

Another point of view that could bring some light to the results of processes that were part of consolidation, were the time trends of timber harvesting. The comparison between the trends in harvesting from forests with different ownership types is presented in Table 2.

\begin{tabular}{|c|c|c|c|}
\hline \multicolumn{4}{|c|}{ 2009-2018 } \\
\hline Harvesting by type of ownership & Coefficients & $P$-value & R Square \\
\hline State ownership & 265.60 & 0.01 & $55.45 \%$ \\
\hline Private ownership & \multicolumn{3}{|c|}{ No trend } \\
\hline Other public ownership & 63.39 & 0.00 & $78.35 \%$ \\
\hline \multicolumn{4}{|c|}{ 2009-2015 } \\
\hline State ownership - nonlinear & Coefficients & P-value & R Square \\
\hline $\mathbf{t}$ & 3169.28 & 0.007 & \multirow{3}{*}{$95,05 \%$} \\
\hline $\mathbf{t}^{2}$ & -492.59 & 0.009 & \\
\hline$t^{3}$ & 0.06 & 0.015 & \\
\hline Private ownership & \multicolumn{3}{|c|}{ No trend } \\
\hline Other public ownership & 65.51 & 0.02 & $78.35 \%$ \\
\hline
\end{tabular}

Source: Author

The results in Table 2 show that the inclusion of the years of consolidation led to stabilizing the trend of harvesting. Production from state-owned forests declined until 2014 and then experienced small ups and downs thereafter. The overall policy in the Bulgarian forests led to stability, i.e. lying on the linear trend. The harvesting from private forests is stable without any improvement over time. It may be assumed that the effect would appear after the current consolidation in 2020. As it was pointed previously the consolidation only slightly slowed down the linear trend of harvesting from forests under other types of public ownership. The problem here is that the productivity is different after 2018. Ups 
and downs do not reveal constant increment of the annual volume harvested, but only the establishment of upward long run tendency through time.

\section{Conclusion}

At this stage, the current study is only the first step in understanding the effects of forest land consolidation in Bulgaria. It may be assumed that the consolidation in the way it is carried out in Bulgaria mainly results in qualitative changes and dynamic stabilization in the long term. Results such as biodiversity conservation and similar will be achieved over time. Meanwhile, no economic results are revealed which show an improvement in the economic situation of the Bulgarian forests sector. As global practice states, consolidation is the first step for improving forest infrastructure and reducing production costs. In Bulgaria, obtaining the benefits from improved productivity, like increased wages for the employees, surpassed the productivity improvement in the years 2016-2018. In this way, quantitative results in a short term are less likely to appear. Changing the share of state forests, despite consolidation in the period 2015-2018 from $72.96 \%$ to $72.2 \%$, implies that the purpose is not to improve the typical state managed forests, but to enlarge forests under other public management (they increased around $1.37 \%$ ). This change of purpose becomes important otherwise the enterprises would take the profits for themselves.

The following additional steps (not officially considered by the EFA or MAFF), supporting the decisions prior to the consolidation process, may be proposed based on the results of the study:

- Wide public discussion about the beneficiaries of consolidated forest use.

- Analysis of what the expected productivity is and how long it will take to be reflected in the wages of people employed in the forestry sector.

- Analysis of the long-term tendencies and stability of the system after the consolidation.

- Comprehensive cost-benefit analysis of the consolidation, which is discussed with the stakeholders.

The implementation of these steps will ensure that the forest land consolidation as a process and venture will not provoke any doubts about the fairness of the decision committed.

\section{Acknowledgments}

This work was supported by the project NIS-B-1074/16.03.2020 'Creating a model for supporting the consolidation of landed properties in forest areas in the Republic of Bulgaria', implemented at the University of Forestry, Sofia, Bulgaria.

\section{References}

Endo, V. (2010). Applying the Land Governance Assessment Frameworkin a Middle-Income Economy: The Case of Peru. Innovations in Land Rights Recognition, Administration, and Governance, A World Bank Study, 281-291

Economic aggregates of forestry.(2020, April 10) Retrieved from Eurostat website:

https://appsso.eurostat.ec.europa.eu/nui/show.do?dataset=for_eco_cp\&lang=en

Hudecova, L. (2015). The Effectiveness of Land Consolidation in Slovakia. FIG Working Week 2015.

Kies, U. \& Peter, A. (2017). Forest land consolidation of community forests in North Rhine-Westphalia, Readjustment of property as a solution for land fragmentation and inactive small-scale private forest owners in Germany. SIMWOOD Pilot Project NRW Summary Report: 3.

Kolis, K., Hiironen, J., Riekkinen, K. \& Vitikainen, A. (2017). Forest land consolidation and its effect on climate. Land Use Policy, (61): 536-542

Kolev, K., \& Yovkov, I. (2011). Social Equilibrium as a Criterion for Sustainable Development of Public Output. Economic Thought journal, Bulgarian Academy of Sciences - Economic Research Institute, (3), 68-91

Order No 49-336-2020. Retreived from: https://tinyurl.com/y5qqzplf

Roundwood removals under bark by type of ownership. (2020, April 15).Retrieved from Eurostat website: https://appsso.eurostat.ec.europa.eu/nui/show.do?dataset=for_owner\&lang=en

Thomas, J. (2004). Modern Land Consolidation: Recent Trends on Land Consolidation in Germany. Proceedings of Symposium on modern land consolidation, Volvic, France: 10-11.

Vitikainen, A. (2004). An Overview of Land Consolidation in Europe. Nordic Journal of Surveying and Real Estate Research, (1): 23-44

Yovkov, I. \& Kolev, V. (2008). Comparative analysis of the models of forests use applied in Bulgaria during the period 1960-1997, Silva Balcanica 9(1):77-83 